\title{
Calcium Valence-to-Core X-ray Emission Spectroscopy: A Sensitive Probe of Oxo Protonation in Structural Models of the Oxygen- Evolving Complex
}

\author{
Zachary Mathe, ${ }^{\dagger}$ Dimitrios A. Pantazis, ${ }^{\ddagger}$ Heui Beom Lee, ${ }^{\S}$ Richard Gnewkow,"

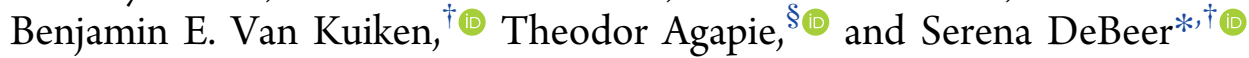 \\ ${ }^{\dagger}$ Max Planck Institute for Chemical Energy Conversion, Stiftstrasse 34-36, D-45470 Mülheim an der Ruhr, Germany
${ }^{\ddagger}$ Max-Planck-Institut für Kohlenforschung, Kaiser-Wilhelm-Platz 1, D-45470 Mülheim an der Ruhr, Germany
${ }^{\S}$ Division of Chemistry and Chemical Engineering, California Institute of Technology, Pasadena, California 91125, United States
${ }^{\|}$Institute of Optics and Atomic Physics, Technical University of Berlin, Hardenbergstraße 36, D-10587 Berlin, Germany
}

Supporting Information

ABSTRACT: Calcium is an abundant, nontoxic metal that finds many roles in synthetic and biological systems including the oxygen-evolving complex (OEC) of photosystem II. Characterization methods for calcium centers, however, are underdeveloped compared to those available for transition metals. Valence-to-core X-ray emission spectroscopy (VtC XES) selectively probes the electronic structure of an element's chemical environment, providing insight that complements the geometric information available from other techniques. Here, the utility of calcium VtC XES is established using an in-house dispersive spectrometer in combination with density functional theory. Spectral trends are rationalized within a molecular orbital framework, and $\mathrm{K} \beta_{2,5}$ transitions, derived from molecular orbitals with primarily ligand $\mathrm{p}$ character, are found to be a promising probe of the calcium coordination environment. In particular, it is shown that calcium VtC XES is sensitive to the electronic structure changes that accompany oxo protonation in $\mathrm{Mn}_{3} \mathrm{CaO}_{4}$-based molecular mimics of the OEC. Through correlation to calculations, the potential of calcium VtC XES to address unresolved questions regarding the mechanism of biological water oxidation is highlighted.

\section{INTRODUCTION}

Calcium, the fifth most abundant element in the earth's crust, fills many important roles in natural and synthetic chemistry. ${ }^{1}$ $\mathrm{Ca}^{2+}$ is the main cation in bone, shell, and microstructured biomaterials with remarkable mechanical properties. ${ }^{1-4}$ It is often employed as an enzymatic cofactor, including within the photosynthetic oxygen-evolving complex (OEC), and is considered "the best communicator" in biological signaling. ${ }^{5-10}$ Calcium is a key component in cements and many industrial chemical processes, and molecular calcium complexes can effect alkene and imine hydrogenations, polymerizations, and even the nucleophilic alkylation of benzene. ${ }^{11-15}$ Partly because it is such a "green" metal compared to the often rare or toxic stalwarts of transition-metal chemistry, interest in calcium catalysts and metal-organic frameworks is increasing. ${ }^{11,14,16-19}$

Despite these important applications, tools for probing the calcium chemical environment remain limited. ${ }^{20}$ As a $\mathrm{d}^{0}$ metal, it is inaccessible by $\mathrm{UV} /$ vis or electron paramagnetic resonance (EPR) spectroscopies, and, hence, solid-state NMR spectroscopy and X-ray absorption spectroscopy (XAS) are the dominant methods for characterization. Calcium XAS, including both K-edge and extended X-ray absorption fine structure (EXAFS) analysis, can provide valuable geometric information, including coordination numbers, bond lengths, and symmetry, but from which limited ligand electronic structure can be inferred. ${ }^{4,21-25}$ The NMR parameters of ${ }^{43} \mathrm{Ca}$ can distinguish similar ligand sets and geometries, even showing sensitivity to changes beyond the first coordination sphere. However, the sparse information obtained in a ${ }^{43} \mathrm{Ca}$ NMR experiment reflects a host of chemical factors that may be difficult to deconvolute. Further, despite recent technological and methodological advances, such experiments remain challenging because of the poor NMR properties $(7 / 2$ nuclear spin and low gyromagnetic ratio) and low natural abundance of ${ }^{43} \mathrm{Ca}^{20,23}$

K-edge valence-to-core X-ray emission spectroscopy (VtC XES) offers a direct probe of an element's coordination environment, including ligand identities and protonation

Received: September 26, 2019

Published: November 19, 2019 
states, and its application to calcium could greatly extend current techniques for the study of calcium systems in general and the OEC in particular. In a K-edge XES experiment, a 1s electron is ionized from the absorbing atom by an X-ray, leaving a core hole; then as another electron fills that hole, a second X-ray is emitted and its energy measured. Such fluorescence processes can be described with a molecular orbital (MO) framework using the canonical orbitals from a density functional theory (DFT) calculation, the eigenvalues of which approximate electron ionization energies.

For calcium $\mathrm{K} \beta$ XES in particular, transitions from $\mathrm{Ca} 3 \mathrm{p}$ orbitals form the intense $\mathrm{K} \beta_{1,3}$ feature; because of the empty $\mathrm{d}$ shell of calcium, the $\mathrm{K} \beta^{\prime}$ feature, which arises from $\mathrm{p}-\mathrm{d}$ exchange in open-shell transition metals, is not observed. VtC transitions contribute weaker satellite peaks, with $\mathrm{K} \beta^{\prime \prime}$ and $\mathrm{K} \beta_{2,5}$ transitions derived from ligand valence $\mathrm{s}$ and $\mathrm{p}$ orbitals, respectively (Figure 1). VtC transitions are dipole-allowed,

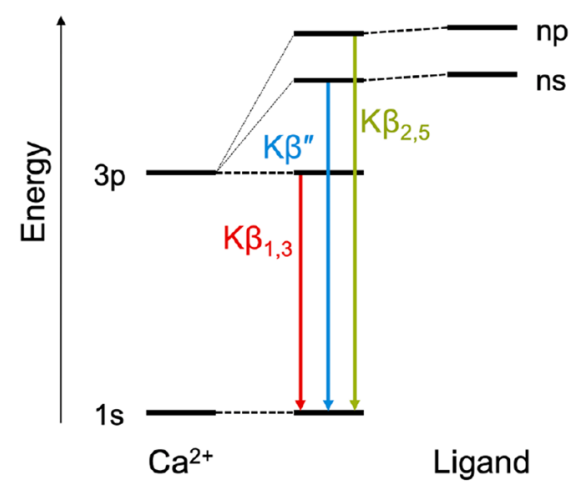

Figure 1. Diagram of calcium $\mathrm{K} \beta$ X-ray emission lines.

with an intensity derived from a small amount of absorber $n \mathrm{p}$ character mixed into the donor orbital. ${ }^{26-29} \mathrm{VtC}$ spectra thus reflect ligand ionization energies, and they can be correlated with calculations to provide a map of (a subset of) the occupied ligand valence MOs. ${ }^{30-32}$ Transition-metal VtC XES has been used to identify a light atom unresolvable by EXAFS $^{33}$ and to measure ligand protonation state ${ }^{34-37}$ and bond activation. ${ }^{38-40}$ Unlike pre-edge XAS, VtC XES is generally not sensitive to the symmetry of the coordination environment. ${ }^{35,41}$

The goal of the present study is to investigate the potential of $\mathrm{VtC} \mathrm{XES}$ as a probe of the calcium coordination environment and specifically to assess its potential relevance to studies of the OEC of photosystem II (PSII), the active site of photosynthetic water oxidation and one of the most important structures in biology. The OEC consists of a $\mathrm{Mn}_{4} \mathrm{CaO}_{5}$ core, arranged as a $\mathrm{Mn}_{3} \mathrm{CaO}_{4}$ cubane connected to the fourth pendant manganese by two oxygen bridges. The calcium is additionally ligated by two protein carboxylates, each bridging the calcium and a manganese, and two water molecules.' In each turnover, the OEC proceeds through the five states $S_{0-4}$, removing four electrons and four protons to convert two substrate water molecules to one oxygen molecule. A great variety of studies across disciplines have elucidated much of the structure and mechanism of the OEC, with EPR and manganese XAS and XES providing the most important spectroscopic contributions. ${ }^{42-49}$ Important questions remain, however, especially regarding the identities of substrate oxygen atoms, bonding arrangements, and oxygen protonation states in the different $S$ states.

Here, we demonstrate that calcium VtC XES, supported by quantum-mechanical calculations, offers a promising probe of $\mathrm{Mn}_{3} \mathrm{CaO}_{4}$ systems. The spectral trends and character of the donor orbitals are established using highly symmetric salts. Then, structural mimics of the OEC, previously developed by Agapie and co-workers, ${ }^{50}$ reveal the sensitivity of the technique to $\mathrm{Mn}_{3} \mathrm{CaO}_{4}$ oxo protonation. Finally, its potential applicability to the OEC is demonstrated using two computational models of the $S_{1}$ state.

\section{MATERIALS AND METHODS}

Samples. Seven calcium salts were studied: the halides $\mathrm{CaF}_{2}$, $\mathrm{CaCl}_{2}, \mathrm{CaBr}_{2}$, and $\mathrm{CaI}_{2}$ and the oxygen-coordinating salts $\mathrm{CaO}$, $\mathrm{Ca}(\mathrm{OH})_{2}$, and $\mathrm{CaCO}_{3}$ (see Table 1 for properties and section $\mathrm{S} 2$ for rendered structures). All salts were purchased from Sigma-Aldrich in the highest-available purity and used without further purification.

Three structural mimics of the OEC were prepared according to published procedures (Figure 2)..$^{50,51}$ They each consist of a $\mathrm{Mn}_{3} \mathrm{CaO}_{4}$ core supported by the 1,3,5-triphenylbenzene-based ligand $\mathrm{L}$, which coordinates to each manganese atom with one pyridyl nitrogen and one alkoxide. Compounds $\mathbf{1}$ and $\mathbf{1 H}$ contain the ligand $N, N^{\prime}$-dimethyl- $N, N^{\prime}$-diacetylethylenediamine dioximate $\left(\mathrm{ON}_{4} \mathrm{O}\right)$, which coordinates to the calcium atom via two amine and two oximate nitrogen lone pairs and to two manganese atoms via the oximate oxygen lone pairs; an acetate bridges the calcium and the third manganese atom. $\mathbf{1 H}$ differs from $\mathbf{1}$ by protonation of the cubane oxygen atom opposite the acetate and by a triflate counterion. In compound 2, three acetates bridge from manganese atoms to the calcium, and a dimethylformamide (DMF) caps the calcium.

Table 1. List of Compounds and Their Properties

\begin{tabular}{|c|c|c|c|c|}
\hline compound $^{a}$ & coordination & $\begin{array}{c}\text { approximate local symmetry at } \\
\text { calcium }\end{array}$ & $\begin{array}{l}\text { halogen Pauling } \\
\text { electronegativity }\end{array}$ & $\begin{array}{c}\text { average } \mathrm{Ca}-\mathrm{X} \text { distance } \\
(\AA)\end{array}$ \\
\hline $\mathrm{CaF}_{2}$ & 8 & $O_{h}$ & 3.98 & 2.366 \\
\hline $\mathrm{CaCl}_{2}$ & 6 & $O_{h} / D_{4 h}$ & 3.16 & 2.745 \\
\hline $\mathrm{CaBr}_{2}$ & 6 & $O_{h} / D_{4 h}$ & 2.96 & 2.885 \\
\hline $\mathrm{CaI}_{2}$ & 6 & $O_{h}$ & 2.66 & 3.117 \\
\hline $\mathrm{CaO}$ & 6 & $O_{h}$ & & 2.405 \\
\hline $\mathrm{Ca}(\mathrm{OH})_{2}$ & 6 & $O_{h} / D_{4 h}$ & & 2.368 \\
\hline $\mathrm{CaCO}_{3}$ & 6 & $O_{h} / D_{4 h}$ & & 2.358 \\
\hline $\mathbf{1}=\mathrm{LMn}_{3} \mathrm{CaO}_{4}\left(\mathrm{ON}_{4} \mathrm{O}\right)(\mathrm{OAc})$ & 8 & $C_{s}$ & & 2.500 \\
\hline $\begin{array}{l}\mathbf{1} \mathbf{H}=\left[\mathrm{LMn}_{3} \mathrm{CaO}_{3}(\mathrm{OH})\left(\mathrm{ON}_{4} \mathrm{O}\right)(\mathrm{OAc})\right] \\
\quad[\mathrm{OTf}]\end{array}$ & 8 & $C_{s}$ & & 2.500 \\
\hline $2=\mathrm{LMn}_{3} \mathrm{CaO}_{4}(\mathrm{OAc})_{3}(\mathrm{DMF})$ & 7 & $C_{s}$ & & 2.406 \\
\hline
\end{tabular}

${ }^{a} \mathrm{OTf}=$ triflate $\mathrm{OAc}=$ acetate $\mathrm{X}=$ any ligand. 


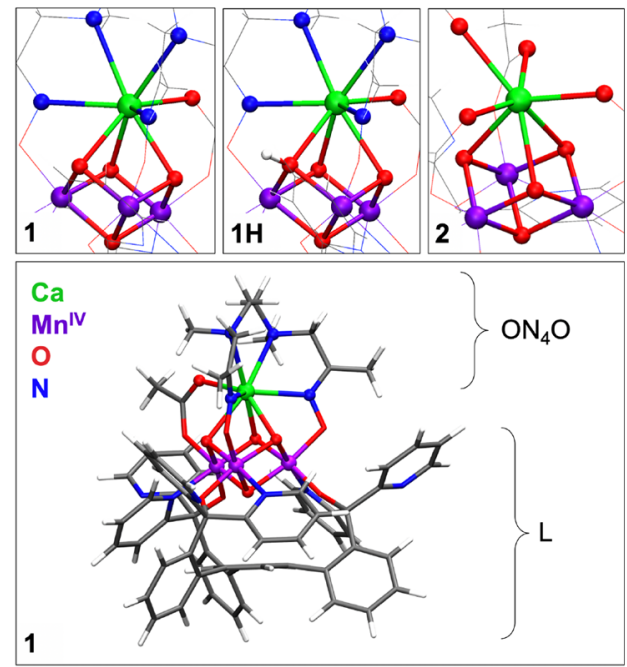

Figure 2. Full structure of $\mathbf{1}$ with the two polydentate ligands, $\mathrm{ON}_{4} \mathrm{O}$ and $\mathrm{L}$, labeled and truncated structures of $1,1 \mathbf{H}$, and 2 .

Samples were prepared with poly(tetrafluoroethylene) or poly(ether ether ketone) (PEEK) cells with windows of either $38-\mu \mathrm{m}$ Kapton tape or $5-\mu \mathrm{m}$ polypropylene film. To avoid spectral broadening due to incident-beam penetration effects, ${ }^{52} \mathrm{CaF}_{2}, \mathrm{CaCl}_{2}$, the oxygen-coordinated salts, and the molecular complexes were prepared as thin powders either spread on Kapton tape or pressed into $100-\mu \mathrm{m}$-deep divots machined into PEEK. $\mathrm{CaBr}_{2}$ and $\mathrm{CaI}_{2}$, which have short attenuation lengths, were pressed into pellets to minimize signal loss due to reabsorption of photons by the heavy halides. Aluminum filters $(800 \mathrm{~nm})$ were used to attenuate $\mathrm{UV} /$ vis fluorescence when necessary. Hygroscopic or oxygen-sensitive samples were prepared in an inert-atmosphere glovebox. To minimize radiation damage, the molecular complexes were mounted on a coldfinger with a base temperature of 11-14 K, although the temperature at the sample was estimated at $60-80 \mathrm{~K}$.

All data were collected using the LabXES, an in-house dispersive spectrometer that utilizes a gallium metal jet X-ray tube to obtain a high incident photon flux and a full-cylinder von Hamos geometry to maximize the solid angle of detection. ${ }^{52,54}$ The source was operated at $250 \mathrm{~W}$, the detector was in the postfocus position, and total collection times ranged from 18 to $136 \mathrm{~h}$ per sample. The sample and spectrometer chamber were kept at pressures of $10^{-7}-10^{-6} \mathrm{mbar}$ to minimize signal attenuation. A single-photon-counting algorithm with manually chosen energy windows was used to reject signals from other elements, and a linear subtraction was applied to remove the background due to randomly oriented photons reflected by the spectrometer chamber. ${ }^{54,55}$ The absolute energy of the instrument was calibrated to the $\mathrm{CaCO}_{3}$ mainline maximum at $4012.2 \mathrm{eV}$, the value of which was obtained by an initial calibration to the secondorder Bragg reflection of the $\mathrm{K} \alpha_{1}$ line of copper metal, set to 4023.9 $\mathrm{eV}$. (The $\mathrm{Cu} \mathrm{K} \alpha_{1}$ line is at $8047.8 \mathrm{eV}^{56}$ ) The absolute energy of the instrument was found to drift between measurements within $\pm 0.2 \mathrm{eV}$ because of mechanical instability in the X-ray source focusing optic. For this reason, all experimental spectra were manually shifted to align the mainlines with that of $\mathrm{CaCO}_{3}(4012.2 \mathrm{eV})$. This allowed us to robustly assess the shift in the $\mathrm{VtC}$ features relative to a fixed mainline position. The sample radiation damage was assessed by comparing partial sum spectra and conservatively discarding data from damaged spots before collecting additional spectra if needed. For example, for complex 1, an initial measurement was performed for $12 \mathrm{~h}$. A spectrum generated from data collected during hours 9-12 was slightly different from spectra generated from hours $0-3,3-6$, and 6-9. All data after hour 8 were discarded, and a further 16 measurements of $8 \mathrm{~h}$ each were performed on fresh sample spots and the resulting spectra summed.
Computational Details. All DFT calculations were performed with the ORCA 4.1 suite of quantum chemistry programs, using a combination of functional, basis sets, and approximations wellestablished for the calculation of transition-metal $\mathrm{VtC}$ XES. $^{26,27,35,57-59}$ The BP86 functional ${ }^{60,61}$ was used together with the zero-order regular approximation (ZORA) ${ }^{62}$ to account for relativistic effects. The D3 dispersion correction ${ }^{63,64}$ was used for geometry optimizations of the molecular complexes, and conductorlike polarizable continuum solvation ${ }^{65}$ was used with an infinite dielectric for molecular complexes and OEC models. Relativistically recontracted ZORA-def2-TZVP basis sets were used for all calculations except that of $\mathrm{CaI}_{2}$ because this basis was unavailable for iodine; for this compound, regular def2-TZVP basis sets were used instead. ${ }^{66}$ The resolution of the identity approximation was employed with SARC $/ \mathrm{J}^{67}\left(\operatorname{def} 2 / \mathrm{J}^{68}\right.$ for $\left.\mathrm{CaI}_{2}\right)$ auxiliary basis sets to reduce the computational cost of calculations. Dense ORCA integration grids were used: Grid7 for calcium and manganese and Grid6 for all other atoms.

Transitions were calculated using a simple one-electron method using canonical ground-state Kohn-Sham (KS) orbitals. ${ }^{35}$ Because test calculations for $\mathrm{CaCl}_{2}, \mathrm{CaCO}_{3}$, and $\mathbf{1 H}$ showed negligible quadrupole contributions to spectra, only dipole transitions were included to reduce computational cost. The characters of the MOs were investigated both by Löwdin population analysis (using cclib ${ }^{69}$ ) and by the plotting of isosurfaces with isovalues of \pm 0.05 (using $\left.\mathrm{VMD}^{70}\right)$. Spectra were calculated from DFT transitions using an asymmetric pseudo-Voigt profile chosen to approximate the unique response function of the LabXES instrument (see section S9). ${ }^{54}$

Calcium salts were modeled using the spin-restricted KS formalism. The crystal environments were approximated using an established embedding scheme to allow direct comparison to molecular systems. ${ }^{24,71-74}$ At the center of each model was a quantum cluster (QC) equipped with the aforementioned basis sets. QCs were centered on a calcium atom and included directly ligating counterions, as well as the nearest three hydroxide ions in each of the adjacent trioctahedral layers in the case of $\mathrm{Ca}(\mathrm{OH})_{2}$. Each $\mathrm{QC}$ was embedded in a spherical region of point charges (PC) with a radius of $50 \AA$. Between the $\mathrm{QC}$ and $\mathrm{PC}$ was a boundary region composed of capped effective core potentials (cECPs), which served to prevent the unphysical flow of electrons from the $\mathrm{QC}$ to the positive point charges. Each cECP consisted of a point charge and a valence-only basis set from the SDD family. ${ }^{75,76}$ Coordinates were obtained from a proton-resolved neutron diffraction structure ${ }^{77}$ for $\mathrm{Ca}(\mathrm{OH})_{2}$ (see section $\mathrm{S} 1$ ) and X-ray diffraction (XRD) structures ${ }^{78-82}$ for all others. Hypothetical $\mathrm{CaCl}_{2}$ and $\mathrm{CaBr}_{2}$ crystals with varying $\mathrm{Ca}-\mathrm{X}$ distances were constructed by scaling the respective embedded model.

Molecular complexes and OEC models were calculated using the spin-unrestricted KS formalism. XRD crystal structures were available for $\mathbf{1 H}$ and a variant of $\mathbf{2}$ with a capping tetrahydrofuran instead of DMF. ${ }^{50}$ These coordinates were used to construct initial guesses for geometry optimizations, with the proton and triflate removed from $\mathbf{1 H}$ to obtain a starting structure for $\mathbf{1}$ and a DMF manually inserted in 2. Optimized $\mathrm{Ca}-\mathrm{O}, \mathrm{Mn}-\mathrm{O}$, and $\mathrm{Mn}-\mathrm{Mn}$ distances in the cubane of $1 \mathbf{H}$ had a mean absolute deviation from those of the crystal structure of $0.007 \AA$, demonstrating the accuracy of the method and validity of the optimized structures of $\mathbf{1}$ and 2 . The published OEC models ${ }^{83}$ were not reoptimized.

For a consistent comparison with the experimental data, all calculated spectra were also manually shifted to align the mainlines with that of $\mathrm{CaCO}_{3}$. Then an absolute energy shift of $+71.1 \mathrm{eV}$ was applied to correct for the errors in core orbital energies inherent in the method, chosen to best align the $\mathrm{K} \beta_{2,5}$ features (see section $\mathrm{S} 1$ ). ${ }^{26,35}$ All observed and calculated spectra were normalized within 3990$4050 \mathrm{eV}$ to an integrated area of 1000 . Peak energies and intensities were obtained after subtraction of the tail of the mainline, fit using two Donaich functions. 


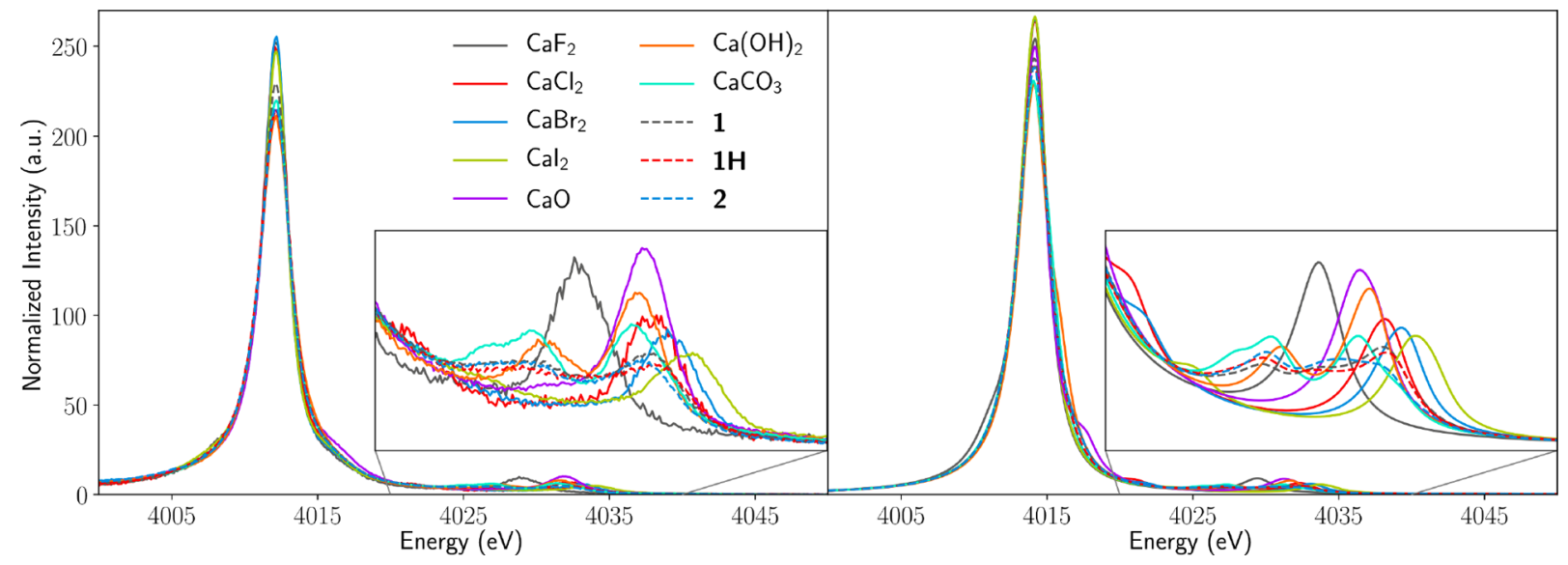

Figure 3. All observed (left) and calculated (right) calcium VtC XES spectra, with the $\mathrm{K} \beta_{2,5}$ regions inset.

\section{RESULTS AND DISCUSSION}

Figure 3 presents normalized calcium $\mathrm{K} \beta$ XES spectra for all species measured in the present study (left panel) and the corresponding DFT calculations (right panel), clearly showing that the general experimental trends are reproduced by theory. The detailed origins of certain features will be discussed in the subsequent sections; here, we briefly summarize the main features. The spectra may be divided into two regions: the mainlines spanning $4005-4024 \mathrm{eV}$ and the $\mathrm{K} \beta_{2,5}$ regions spanning 4024-4038 eV (Figure 3). The mainlines are composed of strong, approximately atomic $\mathrm{K} \beta_{1,3}$ transitions $\left(\mathrm{Ca} 3 \mathrm{p} \rightarrow 1 \mathrm{~s}\right.$ ) at $\sim 4012 \mathrm{eV}$, as well as weaker $\mathrm{K} \beta^{\prime \prime}$ transitions derived from donor orbitals of primarily ligand $s$ character and transitions from multiply excited states. ${ }^{84-86}$ When the calculated spectra are shifted to align the calculated and experimental $\mathrm{K} \beta_{2,5}$ features (vida supra), the calculated mainlines appear blue-shifted by $2 \mathrm{eV}$ with respect to the calculations, reflecting an underestimation of the energy gap between the $\mathrm{Ca} 3 \mathrm{p}$ and ligand valence $\mathrm{p}$ orbitals.

There are notable differences between the general structure of these spectra and that of the transition-metal $\mathrm{VtC}$ spectra: (a) because calcium has no $d$ electrons to exchange-couple with the $\mathrm{p}$ holes of the final states, there are no $\mathrm{K} \beta^{\prime}$ features; (b) the calcium $\mathrm{K} \beta_{2,5}$ features have double the intensity of those typically studied in transition metals; ${ }^{31,38,39,87}$ (c) in transition-metal $\mathrm{VtC} \mathrm{XES}$, the $\mathrm{K} \beta^{\prime \prime}$ peaks are typically energetically separated from the $K \beta_{1,3}$ spectra and have received much attention because of their sensitivity to properties of chemical interest and ready interpretation. ${ }^{33,38,49,88}$ For the present calcium systems, however, $\mathrm{K} \beta^{\prime \prime}$ transitions are not well-resolved from the mainlines, and so the $\mathrm{K} \beta_{2,5}$ features will be the focus of the remaining investigation. (See sections S3 and S4 for the further assignment and discussion of the mainline transitions.) Despite the closed-shell and ionic-bonding nature of $\mathrm{Ca}^{2+}$ (no bonding orbitals involving calcium were found by Pipek-Mezey localization), there is evidently sufficient orbital mixing in both the salts and molecular complexes to allow intense $\mathrm{VtC}$ transitions.

Halide Series. The $\mathrm{K} \beta_{2,5}$ spectra of the calcium halides present a useful series with which to consider the physical origins of transition energies and intensities. Each spectrum consists of a single peak due to transitions from the halide $p$ orbitals, which, in each salt, have approximately equal energy because of the highly symmetric crystal environment (Figure 4). The ligand donor orbitals can be considered mixtures of $\mathrm{X}^{-}$

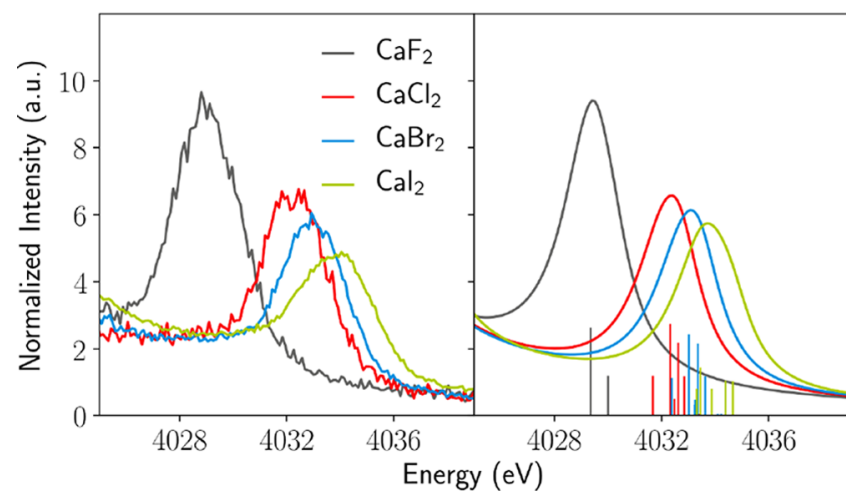

Figure 4. Observed and calculated $\mathrm{K} \beta_{2,5}$ spectra of the calcium halides, with individual calculated transitions plotted as sticks.

highest occupied MOs, and the trend in the peak energies intuitively follows that of the halogen atom electronegativities (Table 1). The more tightly bound p electrons of the lighter halides lie closer in energy to a Ca 1s hole than do those of the later halides, resulting in lower X-ray emission energies.

It is well-understood from transition-metal studies that $\mathrm{VtC}$ transitions are dipole-allowed because of the absorber $p$ character in the valence-hole final state. In terms of MOs constructed from a finite nucleus-centered basis set, a transition from a valence MO to a metal 1s MO has dipole intensity because of small contributions of the metal $p$ basis functions to the valence MO composed primarily of ligandcentered functions. This mixing of the metal $\mathrm{p}$ and ligand valence character is expected to be inversely dependent on both the metal-ligand distance and the energy gap between the corresponding metal and ligand orbitals in the isolatedatom limit.

To investigate the relationship between the $\mathrm{K} \beta_{2,5}$ transitions and bond length, spectra were calculated for a series of hypothetical $\mathrm{CaCl}_{2}$ crystals with varying average $\mathrm{Ca}-\mathrm{Cl}$ distances (Figure 5). The $\mathrm{K} \beta_{2,5}$ peak areas decrease sharply with the distance, as expected from the dependence on the Ca $\mathrm{p}$ character mixed into halide-centered $\mathrm{p}$ MOs. The trend fits well to an exponential decay, a simple function that describes the overlap integral of two spherical orbitals. The $\mathrm{CaCl}_{2}$ and $\mathrm{CaBr}_{2}$ spectra with a $\mathrm{Ca}-\mathrm{X}$ distance of $2.865 \AA$ (green traces in Figure 5) demonstrate the influence of the atomic radius: the larger $\mathrm{Br}^{-}$anion has more orbital mixing with $\mathrm{Ca}^{2+}$, resulting in a $36 \%$ greater peak area. 


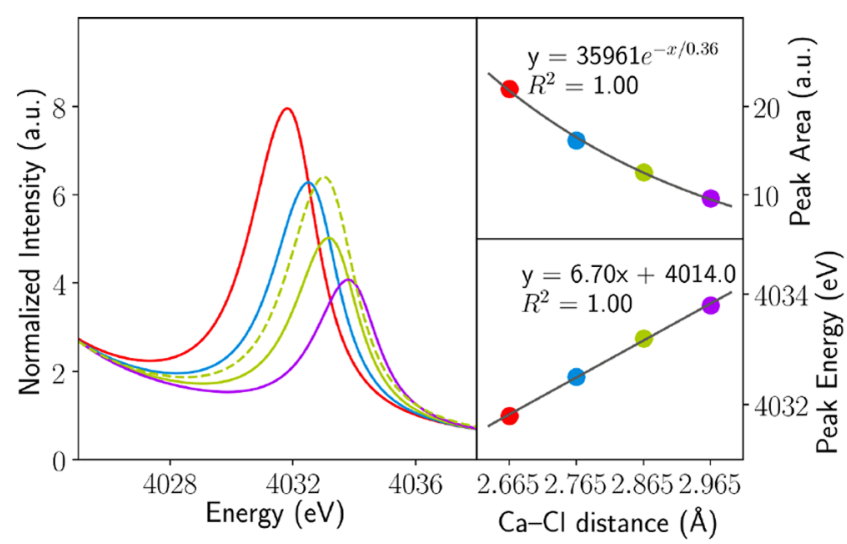

Figure 5. Calculated $\mathrm{K} \beta_{2,5}$ spectra for a series of hypothetical $\mathrm{CaCl}_{2}$ crystals with peak areas and energies correlated to the average $\mathrm{Ca}-\mathrm{Cl}$ distance. A spectrum of $\mathrm{CaBr}_{2}$ with a distance of $2.865 \AA$ (the same distance as the green $\mathrm{CaCl}_{2}$ ) is plotted with a dashed line.

The peak energies decrease linearly at shorter distances, reflecting both stabilization of the $\mathrm{Cl} p$ orbitals by the positively charged calcium and destabilization of the $\mathrm{Ca} 1 \mathrm{~s}$ orbitals by the proximity of the anions (see section S5 for plots of the orbital energies). Compared to that of the $2.765 \AA$ $\mathrm{CaCl}_{2}$ model, the $2.865 \AA \mathrm{CaBr}_{2}$ peak has only a $6 \%$ greater area, yet its energy is $0.4 \mathrm{eV}$ higher. This energy difference confirms that the ligand identity, in addition to the $\mathrm{Ca}$-ligand distance, contributes to the peak energy.

Taken together, the observed and calculated halide $\mathrm{K} \beta_{2,5}$ spectra demonstrate the following: (a) the peak energies reflect both the intrinsic ionization energies of the ligands and the coordination environment; (b) the peak intensities, which depend on the mixing of $\mathrm{Ca} \mathrm{p}$ character into ligand orbitals to produce dipole-allowed transitions, depend on the ligand identity and $\mathrm{Ca}$-ligand distance. In real systems, the ligand identity and bond length are inseparable; we cannot determine, for example, whether the high $\mathrm{K} \beta_{2,5}$ intensity of $\mathrm{CaF}_{2}$ is wholly explicable by the short bonds and small Ca $3 p-X n p$ orbital energy gap or whether the high coordination number is also important.

Oxygen-Coordinating Salts. Observed and calculated $\mathrm{K} \beta_{2,5}$ spectra for the oxygen-coordinated salts are presented in Figure 6, again with good agreement. In each salt, all calcium atoms are equivalent and coordinated to six equidistant oxygen atoms, and the $\mathrm{K} \beta_{2,5}$ transitions derive from valence orbitals that have primarily $\mathrm{O} p$ character. For $\mathrm{CaCO}_{3}$, there are two clearly separated peaks, each with a smaller shoulder. Plotting of the donor orbitals shows that these four features can be assigned to transitions from carbonate MOs with, in order of increasing energy, $\sigma^{*}, \pi, \pi$, and $\pi^{*}$ character (see section S6 for orbital plots).

A comparison between $\mathrm{CaO}$ and $\mathrm{Ca}(\mathrm{OH})_{2}$ provides the first example of the power of calcium VtC XES to resolve oxygen protonation. In the $\mathrm{CaO}$ spectrum, there is a single $\mathrm{K} \beta_{2,5}$ peak, while in $\mathrm{Ca}(\mathrm{OH})_{2}$, the $\mathrm{K} \beta_{2,5}$ region is split into two peaks, the more intense being of energy similar to that of the $\mathrm{CaO}$ peak and the less intense being $4 \mathrm{eV}$ lower. The origin of the $\mathrm{Ca}(\mathrm{OH})_{2}$ splitting is made clear by plotting the donor orbitals. Taking the $\mathrm{O}-\mathrm{H}$ axis as the $z$ axis, the higher-energy peak is composed of transitions from donor orbitals with $\mathrm{O} \mathrm{p}_{x}$ and $\mathrm{p}_{y}$ character, while the lower-energy peak is due to the lowerenergy $\mathrm{O} \mathrm{p}_{z}$ donors, which overlap the protons. The

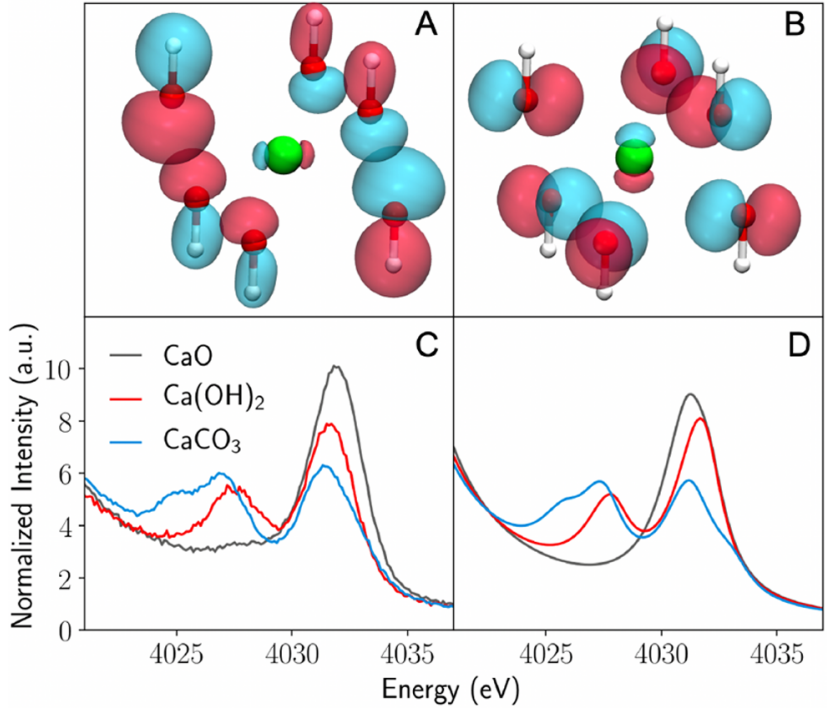

Figure 6. Representative donor orbital plots for the low-energy (A) and high-energy (B) features of $\mathrm{Ca}(\mathrm{OH})_{2}$. Observed (C) and calculated (D) spectra of the oxygen-containing salts.

approximately $2: 1$ intensity ratio is also explained by this model: because each of the three sets of pi orbitals has a similar occupation and orientation with respect to the calcium, each contributes a similar transition intensity. Thus, the spectral splitting reflects stabilization of the $\mathrm{O} \mathrm{p}_{z}$ orbitals by the protons, an effect analogous to stabilization of the hydroxo $s$ orbitals observed in oxo/hydroxo-bridged manganese dimers. ${ }^{34}$

Synthetic Models of the OEC. Having established the spectroscopic and computational methods with simple, symmetric systems, we turn to a series of three structural models of the OEC developed by Agapie and co-workers. ${ }^{50,51}$ The complexes each contain a $\mathrm{Mn}_{3} \mathrm{CaO}_{4}$ core supported at the manganese atoms by the large hexadentate ligand $\mathrm{L}$. In complex $\mathbf{1}$ and its oxo-protonated derivative $\mathbf{1 H}$, the calcium is coordinated by two amine and two oximate nitrogen lone pairs, as well as an acetate. In complex 2 , the calcium is coordinated by three acetates and a DMF.

$\mathrm{K} \beta_{2,5}$ spectra of the molecular complexes are presented in Figure 7. Clear differences are seen among all three in the highenergy region, 4031-4034 eV. The high-energy features are reasonably reproduced by the calculations: there is a decrease in intensity upon protonation of $\mathbf{1}$ to $\mathbf{1 H}$, and the trailing edge of 2 is about $0.4 \mathrm{eV}$ lower in energy. The differences between $\mathbf{1}$

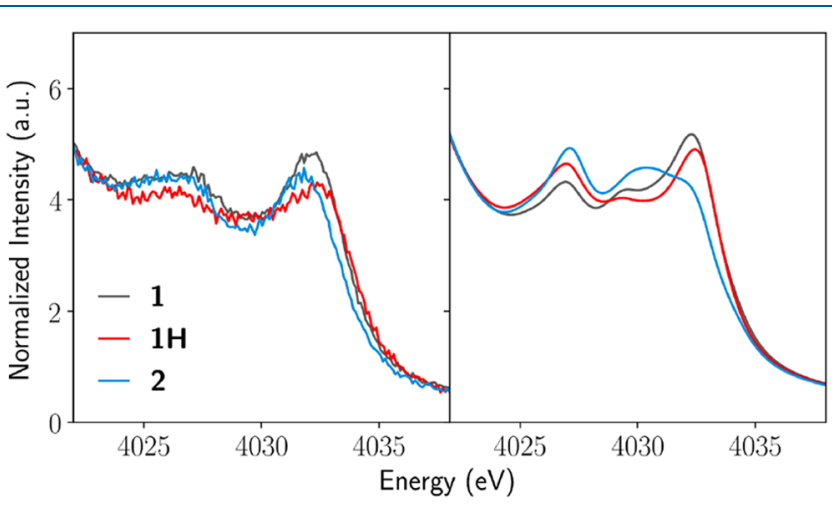

Figure 7. Observed and calculated spectra of the three molecular complexes. 
and $\mathbf{1 H}$ cannot be described as a shift of intensity to lower energy, as might be hypothesized from the case of $\mathrm{CaO}$ and $\mathrm{Ca}(\mathrm{OH})_{2}$, demonstrating the necessity of quantum-chemical calculations in interpreting VtC XES in complex systems.

Upon protonation of $\mathbf{1}$ to $\mathbf{1 H}$, there are significant changes in the molecular geometry around the calcium, including a general expansion of the cubane (Table 2). Two of the cubane

Table 2. Ca-X Distances (Å) in Molecular Complexes

\begin{tabular}{lccc} 
& $\mathbf{1}$ & $\mathbf{1 H}$ & $\mathbf{1 H}-\mathbf{1}$ \\
$\mathrm{Ca}-\mathrm{O} 1$ & 2.410 & 2.505 & +0.095 \\
$\mathrm{Ca}-\mathrm{O}_{2}$ & 2.387 & 2.391 & +0.004 \\
$\mathrm{Ca}-\mathrm{O} 3$ & 2.428 & 2.471 & +0.043 \\
$\mathrm{Ca}-\mathrm{OAc}$ & 2.377 & 2.362 & -0.015 \\
$\mathrm{Ca}-\mathrm{N} 1$ & 2.548 & 2.542 & -0.006 \\
$\mathrm{Ca}-\mathrm{N} 2$ & 2.668 & 2.604 & -0.064 \\
$\mathrm{Ca}-\mathrm{N} 3$ & 2.656 & 2.601 & -0.055 \\
$\mathrm{Ca}-\mathrm{N} 4$ & 2.522 & 2.524 & +0.002 \\
\hline
\end{tabular}

$\mathrm{Ca}-\mathrm{O}$ bond lengths increase, while the $\mathrm{Ca}-\mathrm{N}$ bonds to the $\mathrm{ON}_{4} \mathrm{O}$ amines decrease; the $\mathrm{Ca}-\mathrm{O}$ bond to the protonated oxo (O2) is actually one of the least perturbed distances. To investigate whether the differences in the $\mathrm{K} \beta_{2,5}$ spectra simply reflect the changes in geometry, a spectrum was calculated for $\mathbf{1 n o H}$, a structure of $\mathbf{1}$ constructed by removing the proton and triflate counterion from the optimized structure of $1 \mathbf{H}$, maintaining the zero net charge (Figure 8). The $\mathbf{1 n o H}$

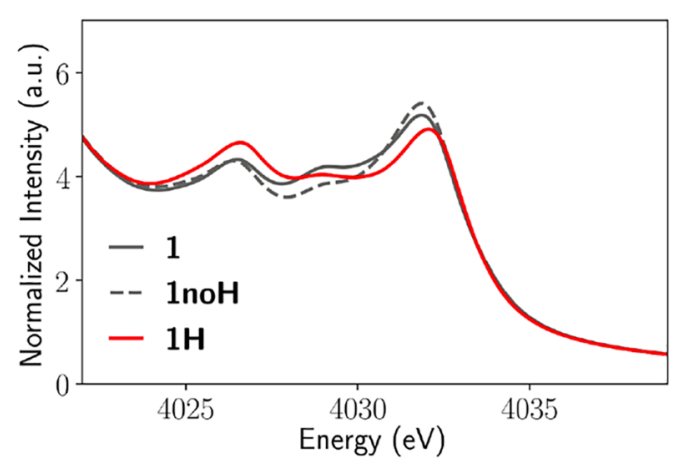

Figure 8. Calculated spectra of $1,1 \mathbf{H}$, and 1 noH, a model constructed by removing the proton and triflate from $\mathbf{1 H}$.

spectrum is less similar to $\mathbf{1 H}$ than $\mathbf{1}$ is in the accurate highenergy region. Thus, calcium $\mathrm{K} \beta_{2,5}$ spectroscopy directly probes the cubane electronic structure and not only the geometry, as is the case for EXAFS or XRD.

In the simple case of the calcium salts, analysis of the donor MOs allowed unambiguous assignment of the spectral features to chemically intuitive aspects of the electronic structure. However, in the case of the OEC model complexes, such results are not obtained because of the mixed character, extreme delocalization, and large number of MOs. (See section S7 for Löwdin decomposition of the donor orbitals of $\mathbf{1}$ and $\mathbf{1 H}$ and a discussion of the limitations of such an analysis.) However, plotting MOs can still provide some qualitative insight into the donor space of these complexes. Using complex 1 as an example, the 79 orbitals with the strongest transition intensities (out of 334 with some intensity) were assigned to one or more of 10 categories to provide a qualitative description of the origins of the spectrum (Figure 9). The high-energy region is composed of donors with cubane antibonding ( $\mathrm{O} \mathrm{p}$ and $\mathrm{Mn} \mathrm{d}$ ), oximate antibonding, and nitrogen lone-pair character.

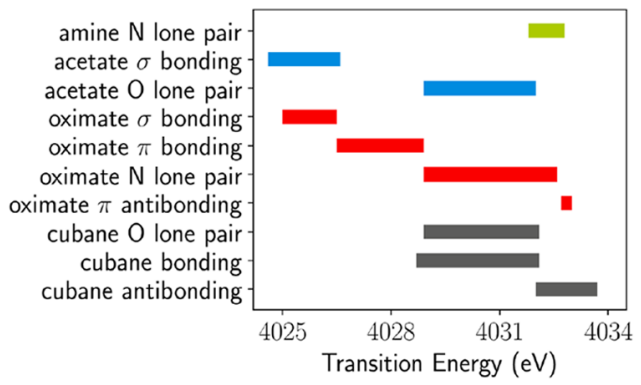

Figure 9. Qualitative orbital character in the $\mathrm{K} \beta_{2,5}$ region of complex 1, determined by visualization of the 79 donor orbitals with the most intense transitions in this energy range.

Clear differences were observed in the high-energy $\mathrm{K} \beta_{2,5}$ features of complexes $\mathbf{1}, \mathbf{1 H}$, and $\mathbf{2}$, and it was shown that the differences reflect changes in the overall cubane electronic structure and not just distortion of the calcium coordination geometry that accompanies protonation. These results demonstrate the potential applicability of calcium VtC XES to the study of complex systems like the OEC.

Computational Models of the $S_{1}$ State of the OEC. Motivated by the good correlation between the experiment and theory in the preceding sections, we now investigate the potential of calcium VtC XES for studies of the OEC. Although $S_{1}$, the dark-stable resting state of PSII, has been the focus of decades of crystallographic and spectroscopic studies, including a $1.95 \AA$ X-ray free electron laser (XFEL) crystal structure, ${ }^{9}$ discrepancies in the data, ${ }^{89,90}$ inconsistencies with otherwise-reliable calculations, ${ }^{83,91-93}$ and inherent limitations of the methods ${ }^{89}$ have kept the exact arrangement and bonding of the OEC unresolved. ${ }^{42}$ A key issue is the position of O5, which in the $1.95 \AA$ structure has $\mathrm{Mn}-\mathrm{O}$ bond distances apparently incompatible with the electronic structure. Spectroscopic and computational studies generally indicate that, while O5 is likely deprotonated in the $S_{1}$ state, the crystal structure reflects some population of an $\mathrm{O} 5$-protonated $\mathrm{S}_{0}$ state and/or heterogeneity in the $S_{1}$ state itself. $42,83,89,91,93-99$ A significant hindrance to study of the $S_{1}$ state is its $S=0$ total spin, which severely limits the application of EPR. Hence, there is a clear demand for novel approaches to characterize the $S_{1}$ state.

To demonstrate the potential for calcium $\mathrm{VtC}$ XES to contribute to our understanding of PSII, spectra were calculated using two models of the $S_{1}$ state, published in a 2015 study by Krewald and co-workers (Figure 10). ${ }^{83}$ The authors constructed a series of models of the active site of PSII
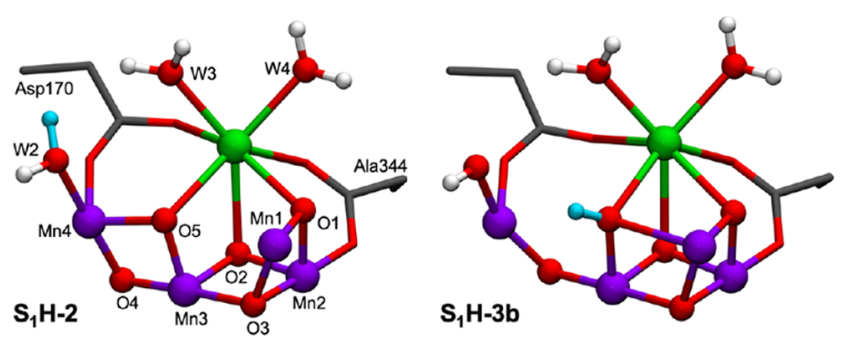

Figure 10. Truncated structures of the two computational models of the OEC, $\mathbf{S}_{\mathbf{1}} \mathbf{H}-\mathbf{2}$ and $\mathbf{S}_{\mathbf{1}} \mathbf{H}-\mathbf{3 b}$. 
based on extensive prior work and with particular care to avoid artifactual rearrangement of the calcium environment; models include eight crystallographic water molecules and all secondsphere residues hydrogen-bonded to ligands of the first coordination sphere. The two models evaluated here, $\mathbf{S}_{\mathbf{1}} \mathbf{H}-\mathbf{2}$ and $\mathbf{S}_{1} \mathbf{H}-3 \mathbf{b}$, are tautomers that differ by the protonation and bonding of O5 and W2: in $\mathrm{S}_{1} \mathrm{H}-2, \mathrm{O} 5$ is a $\mu_{3}$-oxo and bonded to $\mathrm{Ca}, \mathrm{Mn} 3$, and $\mathrm{Mn} 4$, while in $\mathrm{S}_{\mathbf{1}} \mathbf{H}-\mathbf{3 b}$, it is a $\mu_{3}$-hydroxo bonded to $\mathrm{Ca}, \mathrm{Mn} 3$, and $\mathrm{Mn} 1$. For these calculations, a narrower, symmetric line-broadening function was used to demonstrate the data quality that might be obtained using a high-resolution Bragg optic rather than the highly annealed pyrolitic graphite optic employed in the present study (see section S9).

The calculated $S_{1}$ spectra are clearly distinguishable (Figure 11): the high-energy feature has similar intensity in both

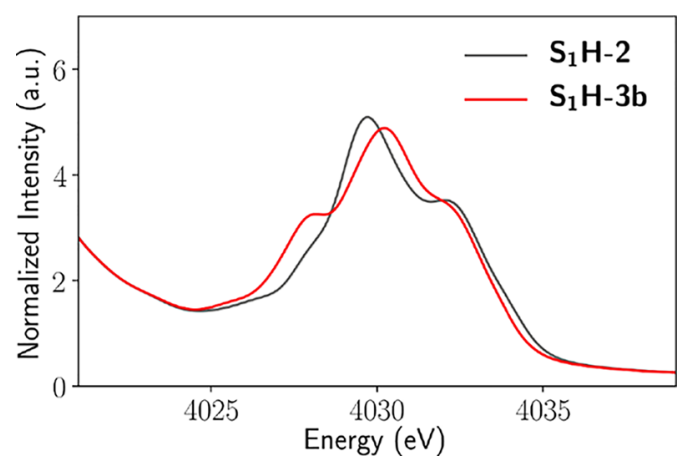

Figure 11. $\mathrm{K} \beta_{2,5}$ spectra of the two $\mathrm{S}_{1}$ state models, calculated with a high-resolution symmetric line-broadening function.

models, while the trailing edge is shifted $0.2 \mathrm{eV}$ lower in $\mathbf{S}_{1} \mathbf{H}$ $\mathbf{3 b}$, and the middle- and lower-energy features have dramatic changes. The relative differences in the spectra are dissimilar to those observed between $\mathbf{1}$ and $\mathbf{1 H}$, again demonstrating the complex, nonlocal effects of oxygen protonation observed in the molecular compounds.

\section{CONCLUSIONS}

Calcium VtC XES has been established as a sensitive probe of the calcium coordination environment, utilizing a unique inhouse dispersive spectrometer in combination with DFT calculations. First, examination of a series of binary salts revealed the character of $\mathrm{K} \beta_{2,5}$ features within an intuitive $\mathrm{MO}$ framework. Spectra of $\mathrm{Mn}_{3} \mathrm{CaO}_{4}$ molecular systems showed the sensitivity of the technique in complex environments, in particular to the effects of cubane oxo protonation. Metalligand covalency is evidently not necessary for VtC XES to report on the ligand electronic structure. Improved methods of transition analysis for such systems with highly delocalized canonical orbitals are under development in our laboratories.

Spectra calculated for two models of the $S_{1}$ state of PSII demonstrated the theoretical power of calcium VtC XES to probe unresolved structural features of the OEC. As shown in a calcium EXAFS study, it is possible to produce active PSII depleted of all calcium atoms except two: the one of interest in the OEC, plus another in the light-harvesting complex II. ${ }^{21}$ Thus, with the high flux and energy resolution available at modern synchrotron and XFEL beamlines, calcium VtC XES experiments on PSII are technically plausible and could make important contributions to our understanding of biological water splitting.

\section{ASSOCIATED CONTENT}

\section{Supporting Information}

The Supporting Information is available free of charge on the ACS Publications website at DOI: 10.1021/acs.inorgchem.9b02866.

Computational details, analysis of the $\mathrm{Ca} \mathrm{K} \beta$ mainlines, $\mathrm{MO}$ population analysis, and additional figures mentioned in the main text (PDF)

\section{AUTHOR INFORMATION}

\section{Corresponding Author}

*E-mail: serena.debeer@cec.mpg.de.

ORCID $\odot$

Dimitrios A. Pantazis: 0000-0002-2146-9065

Benjamin E. Van Kuiken: 0000-0002-3650-7765

Theodor Agapie: 0000-0002-9692-7614

Serena DeBeer: 0000-0002-5196-3400

Notes

The authors declare no competing financial interest.

\section{ACKNOWLEDGMENTS}

The authors acknowledge the Max Planck Society for funding. Z.M. thanks Yvonne Brandenburger and Fabian Strunk for technical expertise with the LabXES spectrometer, as well as Dr. Ragnar Bjornsson and Dr. Vijay Chilkuri for discussions of MO theory. Z.M. acknowledges the Deutscher Akademischer Austauschdienst for M.Sc. scholarship funding. T.A. is grateful to the NIH (Grant R01-GM102687B) for supporting the synthetic model studies.

\section{REFERENCES}

(1) Greenwood, N. N.; Earnshaw, A. Chemistry of the Elements, 2nd ed.; Elsevier Science, 2012.

(2) Weaver, J. C.; Milliron, G. W.; Miserez, A.; Evans-Lutterodt, K.; Herrera, S.; Gallana, I.; Mershon, W. J.; Swanson, B.; Zavattieri, P.; DiMasi, E.; Kisailus, D. The Stomatopod Dactyl Club: A Formidable Damage-Tolerant Biological Hammer. Science 2012, 336, 1275-1280.

(3) Barthelat, F.; Rabiei, R. Toughness Amplification in Natural Composites. J. Mech. Phys. Solids 2011, 59, 829-840.

(4) Laurencin, D.; Wong, A.; Chrzanowski, W.; Knowles, J. C.; Qiu, D.; Pickup, D. M.; Newport, R. J.; Gan, Z.; Duer, M. J.; Smith, M. E. Probing the Calcium and Sodium Local Environment in Bones and Teeth Using Multinuclear Solid State NMR and X-Ray Absorption Spectroscopy. Phys. Chem. Chem. Phys. 2010, 12, 1081-1091.

(5) Brini, M.; Ottolini, D.; Calì, T.; Carafoli, E. Calcium in Health and Disease. In Interrelations between Essential Metal Ions and Human Diseases; Sigel, A., Sigel, H., Sigel, R. K. O., Eds.; Springer: Dordrecht, The Netherlands, 2013; pp 81-137.

(6) Xu, C.; Yang, L.; Yu, J. G.; Liao, R. Z. What Roles Do the Residue Asp229 and the Coordination Variation of Calcium Play of the Reaction Mechanism of the Diisopropyl-Fluorophosphatase? A DFT Investigation. Theor. Chem. Acc. 2016, 135, 1-11.

(7) Deshpande, C. N.; Ruwe, T. A.; Shawki, A.; Xin, V.; Vieth, K. R.; Valore, E. V.; Qiao, B.; Ganz, T.; Nemeth, E.; Mackenzie, B.; Jormakka, M. Calcium Is an Essential Cofactor for Metal Efflux by the Ferroportin Transporter Family. Nat. Commun. 2018, 9. DOI: $10.1038 / \mathrm{s} 41467-018-05446-4$

(8) Yong, S. C.; Roversi, P.; Lillington, J.; Rodriguez, F.; Krehenbrink, M.; Zeldin, O. B.; Garman, E. F.; Lea, S. M.; Berks, B. C. A Complex Iron-Calcium Cofactor Catalyzing Phosphotransfer Chemistry. Science 2014, 345, 1170-1173. 
(9) Suga, M.; Akita, F.; Hirata, K.; Ueno, G.; Murakami, H.; Nakajima, Y.; Shimizu, T.; Yamashita, K.; Yamamoto, M.; Ago, H.; Shen, J. R. Native Structure of Photosystem II at $1.95 \mathrm{~A}^{\circ}$ Resolution Viewed by Femtosecond X-Ray Pulses. Nature 2015, 517, 99-103.

(10) Carafoli, E.; Krebs, J. Why Calcium? How Calcium Became the Best Communicator. J. Biol. Chem. 2016, 291, 20849-20857.

(11) Bauer, H.; Alonso, M.; Fischer, C.; Rösch, B.; Elsen, H.; Harder, S. Simple Alkaline-Earth Metal Catalysts for Effective Alkene Hydrogenation. Angew. Chem., Int. Ed. 2018, 57, 15177-15182.

(12) Platero Prats, A. E.; de la Peña-O'Shea, V. A.; Iglesias, M.; Snejko, N.; Monge, Á.; Gutiérrez-Puebla, E. Heterogeneous Catalysis with Alkaline-Earth Metal-Based MOFs: A Green Calcium Catalyst. ChemCatChem 2010, 2, 147-149.

(13) Wilson, A. S. S.; Hill, M. S.; Mahon, M. F.; Dinoi, C.; Maron, L. Organocalcium-Mediated Nucleophilic Alkylation of Benzene. Science 2017, 358, 1168-1171.

(14) Albrecht, M.; Bedford, R.; Plietker, B. Catalytic and Organometallic Chemistry of Earth-Abundant Metals. Organometallics 2014, 33, 5619-5621.

(15) Bauer, H.; Alonso, M.; Färber, C.; Elsen, H.; Pahl, J.; Causero, A.; Ballmann, G.; De Proft, F.; Harder, S. Imine Hydrogenation with Simple Alkaline Earth Metal Catalysts. Nat. Catal. 2018, 1, 40-47.

(16) Hill, M. S.; Liptrot, D. J.; Weetman, C. Alkaline Earths as Main Group Reagents in Molecular Catalysis. Chem. Soc. Rev. 2016, 45, 972-988.

(17) Levine, D. J.; Gonzalez, M. I.; Legendre, C. M.; Runčevski, T.; Oktawiec, J.; Colwell, K. A.; Long, J. R. Calcium Coordination Solids for $\mathrm{pH}$-Triggered Release of Olsalazine. ChemMedChem 2017, 12, 1739-1742.

(18) Miller, S. R.; Alvarez, E.; Fradcourt, L.; Devic, T.; Wuttke, S.; Wheatley, P. S.; Steunou, N.; Bonhomme, C.; Gervais, C.; Laurencin, D.; Morris, R. E.; Vimont, A.; Daturi, M.; Horcajada, P.; Serre, C. A Rare Example of a Porous Ca-MOF for the Controlled Release of Biologically Active NO. Chem. Commun. 2013, 49, 7773-7775.

(19) Banerjee, D.; Simon, C. M.; Plonka, A. M.; Motkuri, R. K.; Liu, J.; Chen, X.; Smit, B.; Parise, J. B.; Haranczyk, M.; Thallapally, P. K. Metal-Organic Framework with Optimally Selective Xenon Adsorption and Separation. Nat. Commun. 2016, 7, 1-7.

(20) Laurencin, D.; Smith, M. E. Development $\mathrm{Of}^{43} \mathrm{Ca}$ Solid State NMR Spectroscopy as a Probe of Local Structure in Inorganic and Molecular Materials. Prog. Nucl. Magn. Reson. Spectrosc. 2013, 68, 140.

(21) Cinco, R. M.; McFarlane Holman, K. L.; Robblee, J. H.; Yano, J.; Pizarro, S. A.; Bellacchio, E.; Sauer, K.; Yachandra, V. K. Calcium EXAFS Establishes the Mn-Ca Cluster in the Oxygen-Evolving Complex of Photosystem II. Biochemistry 2002, 41, 12928-12933.

(22) Cinco, R. M.; Robblee, J. H.; Messinger, J.; Fernandez, C.; Holman, K. L. M.; Sauer, K.; Yachandra, V. K. Orientation of Calcium in the $\mathrm{Mn}_{4} \mathrm{Ca}$ Cluster of the Oxygen-Evolving Complex Determined Using Polarized Strontium EXAFS of Photosystem II Membranes ${ }^{\dagger}$. Biochemistry 2004, 43, 13271-13282.

(23) Chen, S.; Lucier, B. E. G.; Chen, M.; Terskikh, V. V.; Huang, Y. Probing Calcium-Based Metal-Organic Frameworks via Natural Abundance ${ }^{43} \mathrm{Ca}$ Solid-State NMR Spectroscopy. Chem. a Eur. J. 2018, 24, 8732-8736.

(24) Martin-Diaconescu, V.; Gennari, M.; Gerey, B.; Tsui, E.; Kanady, J.; Tran, R.; Pécaut, J.; Maganas, D.; Krewald, V.; Gouré, E.; Duboc, C.; Yano, J.; Agapie, T.; Collomb, M.-N.; DeBeer, S. Ca KEdge XAS as a Probe of Calcium Centers in Complex Systems. Inorg. Chem. 2015, 54, 1283-1292.

(25) Jalilehvand, F.; Spångberg, D.; Lindqvist-Reis, P.; Hermansson, K.; Persson, I.; Sandström, M. Hydration of the Calcium Ion. An EXAFS, Large-Angle X-Ray Scattering, and Molecular Dynamics Simulation Study. J. Am. Chem. Soc. 2001, 123, 431-441.

(26) Pollock, C. J.; DeBeer, S. Insights into the Geometric and Electronic Structure of Transition Metal Centers from Valence-toCore X-Ray Emission Spectroscopy. Acc. Chem. Res. 2015, 48, 29672975.
(27) Beckwith, M. A.; Roemelt, M.; Collomb, M.-N.; DuBoc, C.; Weng, T.-C.; Bergmann, U.; Glatzel, P.; Neese, F.; DeBeer, S. Manganese K $\beta$ X-Ray Emission Spectroscopy As a Probe of MetalLigand Interactions. Inorg. Chem. 2011, 50, 8397-8409.

(28) Delgado-Jaime, M. U.; DeBeer, S.; Bauer, M. Valence-to-Core $\mathrm{X}$-Ray Emission Spectroscopy of Iron-Carbonyl Complexes: Implications for the Examination of Catalytic Intermediates. Chem. - Eur. J. 2013, 19, 15888-15897.

(29) Smolentsev, G.; Soldatov, A. V.; Messinger, J.; Merz, K.; Weyhermüller, T.; Bergmann, U.; Pushkar, Y.; Yano, J.; Yachandra, V. K.; Glatzel, P. X-Ray Emission Spectroscopy to Study Ligand Valence Orbitals in Mn Coordination Complexes. J. Am. Chem. Soc. 2009, 131, 13161-13167.

(30) Pollock, C. J.; DeBeer, S. Valence-to-Core X-Ray Emission Spectroscopy: A Sensitive Probe of the Nature of a Bound Ligand. J. Am. Chem. Soc. 2011, 133, 5594-5601.

(31) Lancaster, K. M.; Finkelstein, K. D.; DeBeer, S. K $\beta$ X-Ray Emission Spectroscopy Offers Unique Chemical Bonding Insights: Revisiting the Electronic Structure of Ferrocene. Inorg. Chem. 2011, 50, 6767-6774.

(32) Swarbrick, J. C.; Kvashnin, Y.; Schulte, K.; Seenivasan, K.; Lamberti, C.; Glatzel, P. Ligand Identification in Titanium Complexes Using X-Ray Valence-to-Core Emission Spectroscopy. Inorg. Chem. 2010, 49, 8323-8332.

(33) Lancaster, K. M.; Roemelt, M.; Ettenhuber, P.; Hu, Y.; Ribbe, M. W.; Neese, F.; Bergmann, U.; DeBeer, S. X-Ray Emission Spectroscopy Evidences a Central Carbon in the Nitrogenase IronMolybdenum Cofactor. Science 2011, 334, 974-977.

(34) Lassalle-Kaiser, B.; Boron, T. T.; Krewald, V.; Kern, J.; Beckwith, M. A.; Delgado-Jaime, M. U.; Schroeder, H.; Alonso-Mori, R.; Nordlund, D.; Weng, T. C.; Sokaras, D.; Neese, F.; Bergmann, U.; Yachandra, V. K.; DeBeer, S.; Pecoraro, V. L.; Yano, J. Experimental and Computational X-Ray Emission Spectroscopy as a Direct Probe of Protonation States in Oxo-Bridged $\mathrm{Mn}^{\mathrm{IV}}$ Dimers Relevant to Redox-Active Metalloproteins. Inorg. Chem. 2013, 52, 12915-12922.

(35) Lee, N.; Petrenko, T.; Bergmann, U.; Neese, F.; DeBeer, S. Probing Valence Orbital Composition with Iron K-Beta X-Ray Emission Spectroscopy. J. Am. Chem. Soc. 2010, 132, 9715-9727.

(36) Kropp, H.; King, A. E.; Khusniyarov, M. M.; Heinemann, F. W.; Lancaster, K. M.; Debeer, S.; Bill, E.; Meyer, K. Manganese Nitride Complexes in Oxidation States III, IV, and V: Synthesis and Electronic Structure. J. Am. Chem. Soc. 2012, 134, 15538-15544.

(37) Martinie, R. J.; Blaesi, E. J.; Bollinger, J. M.; Krebs, C.; Finkelstein, K. D.; Pollock, C. J. Two-Color Valence-to-Core X-Ray Emission Spectroscopy Tracks Cofactor Protonation State in a Class I Ribonucleotide Reductase. Angew. Chem., Int. Ed. 2018, 57, 1275412758 .

(38) Pollock, C. J.; Grubel, K.; Holland, P. L.; DeBeer, S. Experimentally Quantifying Small-Molecule Bond Activation Using Valence-to-Core X-Ray Emission Spectroscopy. J. Am. Chem. Soc. 2013, 135, 11803-11808.

(39) Rees, J. A.; Martin-Diaconescu, V.; Kovacs, J. A.; DeBeer, S. XRay Absorption and Emission Study of Dioxygen Activation by a Small-Molecule Manganese Complex. Inorg. Chem. 2015, 54, 64106422.

(40) Lu, T. Te; Weng, T. C.; Liaw, W. F. X-Ray Emission Spectroscopy: A Spectroscopic Measure for the Determination of NO Oxidation States in Fe-NO Complexes. Angew. Chem., Int. Ed. 2014, 53, 11562-11566.

(41) March, A. M.; Assefa, T. A.; Bressler, C.; Doumy, G.; Galler, A.; Gawelda, W.; Kanter, E. P.; Németh, Z.; Pápai, M.; Southworth, S. H.; Young, L.; Vankó, G. Feasibility of Valence-to-Core X-Ray Emission Spectroscopy for Tracking Transient Species. J. Phys. Chem. C 2015, 119, 14571-14578.

(42) Pantazis, D. A. Missing Pieces in the Puzzle of Biological Water Oxidation. ACS Catal. 2018, 8, 9477-9507.

(43) Vinyard, D. J.; Brudvig, G. W. Progress Toward a Molecular Mechanism of Water Oxidation in Photosystem II. Annu. Rev. Phys. Chem. 2017, 68, 101-116. 
(44) Peloquin, J. M.; Campbell, K. A.; Randall, D. W.; Evanchik, M. A.; Pecoraro, V. L.; Armstrong, W. H.; Britt, R. D. ${ }^{55} \mathrm{Mn}$ ENDOR of the S2-State Multiline EPR Signal of Photosystem II: Implications on the Structure of the Tetranuclear Mn Cluster. J. Am. Chem. Soc. 2000, 122, 10926-10942.

(45) Cox, N.; Retegan, M.; Neese, F.; Pantazis, D. A.; Boussac, A.; Lubitz, W. Electronic Structure of the Oxygen-Evolving Complex in Photosystem II Prior to O-O Bond Formation. Science 2014, 345, 804-808.

(46) Zaharieva, I.; Chernev, P.; Berggren, G.; Anderlund, M.; Styring, S.; Dau, H.; Haumann, M. Room-Temperature EnergySampling K $\beta$ X-Ray Emission Spectroscopy of the $\mathrm{Mn}_{4} \mathrm{Ca}$ Complex of Photosynthesis Reveals Three Manganese-Centered Oxidation Steps and Suggests a Coordination Change Prior to O2 Formation. Biochemistry 2016, 55, 4197-4211.

(47) Haumann, M.; Müller, C.; Liebisch, P.; Iuzzolino, L.; Dittmer, J.; Grabolle, M.; Neisius, T.; Meyer-Klaucke, W.; Dau, H. Structural and Oxidation State Changes of the Photosystem II Manganese Complex in Four Transitions of the Water Oxidation Cycle $\left(S_{0} \rightarrow S_{1}\right.$, $S_{1} \rightarrow S_{2}, S_{2} \rightarrow S_{3}$, and $S_{3,4} \rightarrow S_{0}$ ) Characterized by X-Ray Absorption Spectroscopy at $20 \mathrm{~K}$ and Room Temperature. Biochemistry 2005, 44, 1894-1908.

(48) Grundmeier, A.; Dau, H. Structural Models of the Manganese Complex of Photosystem II and Mechanistic Implications. Biochim. Biophys. Acta, Bioenerg. 2012, 1817, 88-105.

(49) Pushkar, Y.; Long, X.; Glatzel, P.; Brudvig, G. W.; Dismukes, G. C.; Collins, T. J.; Yachandra, V. K.; Yano, J.; Bergmann, U. Direct Detection of Oxygen Ligation to the $\mathrm{Mn}_{4} \mathrm{Ca}$ Cluster of Photosystem II by X-Ray Emission Spectroscopy. Angew. Chem., Int. Ed. 2010, 49, 800-803.

(50) Kanady, J. S.; Lin, P.-H.; Carsch, K. M.; Nielsen, R. J.; Takase, M. K.; Goddard, W. A.; Agapie, T. Toward Models for the Full Oxygen-Evolving Complex of Photosystem II by Ligand Coordination to Lower the Symmetry of the $\mathrm{Mn} 3 \mathrm{CaO} 4$ Cubane: Demonstration That Electronic Effects Facilitate Binding of a Fifth Metal. J. Am. Chem. Soc. 2014, 136, 14373-14376.

(51) Kanady, J. S.; Tsui, E. Y.; Day, M. W.; Agapie, T. A Synthetic Model of the Mn3Ca Subsite of the Oxygen-Evolving Complex in Photosystem II. Science 2011, 333, 733-736.

(52) Malzer, W.; Grötzsch, D.; Gnewkow, R.; Schlesiger, C.; Kowalewski, F.; Van Kuiken, B.; DeBeer, S.; Kanngießer, B. A Laboratory Spectrometer for High Throughput X-Ray Emission Spectroscopy in Catalysis Research. Rev. Sci. Instrum. 2018, 89, 113111.

(53) Allred, A. L. Electronegativity Values From Thermochemical Data. J. Inorg. Nucl. Chem. 1961, 17, 215-221.

(54) Anklamm, L.; Schlesiger, C.; Malzer, W.; Grotzsch, D.; Neitzel, M.; Kanngiesser, B. A Novel von Hamos Spectrometer for Efficient XRay Emission Spectroscopy in the Laboratory. Rev. Sci. Instrum. 2014, $85,053110$.

(55) Baumann, J.; Gnewkow, R.; Staeck, S.; Szwedowski-Rammert, V.; Schlesiger, C.; Mantouvalou, I.; Kanngießer, B. Photon Event Evaluation for Conventional Pixelated Detectors in Energy-Dispersive X-Ray Applications. J. Anal. At. Spectrom. 2018, 33, 2043-2052.

(56) Deutsch, M.; Holzer, G.; Hartwig, J.; Wolf, J.; Fritsch, M.; Forster, E. K $\alpha$ and $\mathrm{K} \beta$ X-Ray Emission Spectra of Copper. Phys. Rev. A: At., Mol., Opt. Phys. 1995, 51, 283.

(57) Neese, F. The ORCA Program System. Wiley Interdiscip. Rev. Comput. Mol. Sci. 2012, 2, 73-78.

(58) Hugenbruch, S.; Shafaat, H. S.; Krämer, T.; Delgado-Jaime, M. U.; Weber, K.; Neese, F.; Lubitz, W.; Debeer, S. In Search of Metal Hydrides: An X-Ray Absorption and Emission Study of [NiFe] Hydrogenase Model Complexes. Phys. Chem. Chem. Phys. 2016, 18, 10688-10699.

(59) Martin-Diaconescu, V.; Chacón, K. N.; Delgado-Jaime, M. U.; Sokaras, D.; Weng, T. C.; DeBeer, S.; Blackburn, N. J. K $\beta$ Valence to Core X-Ray Emission Studies of $\mathrm{Cu}(\mathrm{I})$ Binding Proteins with Mixed Methionine - Histidine Coordination. Relevance to the Reactivity of the M- and H-Sites of Peptidylglycine Monooxygenase. Inorg. Chem. 2016, 55, 3431-3439.

(60) Perdew, J. P. Density-Functional Approximation for the Correlation Energy of the Inhomogeneous Electron Gas. Phys. Rev. B: Condens. Matter Mater. Phys. 1986, 33, 8822-8824.

(61) Becke, A. D. Density-Functional Exchange-Energy Approximation with Correct Asymptotic Behavior. Phys. Rev. A: At., Mol., Opt. Phys. 1988, 38, 3098-3100.

(62) van Wüllen, C. Molecular Density Functional Calculations in the Regular Relativistic Approximation: Method, Application to Coinage Metal Diatomics, Hydrides, Fluorides and Chlorides, and Comparison with First-Order Relativistic Calculations. J. Chem. Phys. 1998, 109, 392-399.

(63) Grimme, S.; Ehrlich, S.; Goerigk, L. Effect of the Damping Function in Dispersion Corrected Density Functional Theory. J. Comput. Chem. 2011, 32, 1456.

(64) Grimme, S.; Antony, J.; Ehrlich, S.; Krieg, H. A Consistent and Accurate Ab Initio Parametrization of Density Functional Dispersion Correction (DFT-D) for the 94 Elements H-Pu. J. Chem. Phys. 2010, 132, 154104.

(65) Cossi, M.; Rega, N.; Scalmani, G.; Barone, V. Energies, Structures, and Electronic Properties of Molecules in Solution with the C-PCM Solvation Model. J. Comput. Chem. 2003, 24, 669-681.

(66) Weigend, F.; Ahlrichs, R. Balanced Basis Sets of Split Valence, Triple Zeta Valence and Quadruple Zeta Valence Quality for $\mathrm{H}$ to Rn: Design and Assessment of Accuracy. Phys. Chem. Chem. Phys. 2005, 7, 3297-3305.

(67) Pantazis, D. A.; Chen, X. Y.; Landis, C. R.; Neese, F. AllElectron Scalar Relativistic Basis Sets for Third-Row Transition Metal Atoms. J. Chem. Theory Comput. 2008, 4, 908-919.

(68) Weigend, F. Accurate Coulomb-Fitting Basis Sets for H to Rn. Phys. Chem. Chem. Phys. 2006, 8, 1057-1065.

(69) O’boyle, N. M.; Tenderholt, A. L.; Langner, K. M. Cclib: A Library for Package-Independent Computational Chemistry Algorithms. J. Comput. Chem. 2008, 29, 839-845.

(70) Humphrey, W.; Dalke, A.; Schulten, K. VMD: Visual Molecular Dynamics. J. Mol. Graphics 1996, 14, 33-38.

(71) Maganas, D.; DeBeer, S.; Neese, F. Restricted Open-Shell Configuration Interaction Cluster Calculations of the L-Edge X-Ray Absorption Study of $\mathrm{TiO}_{2}$ and $\mathrm{CaF}_{2}$ Solids. Inorg. Chem. 2014, 53, 6374-6385.

(72) Maganas, D.; Roemelt, M.; Hävecker, M.; Trunschke, A.; Knop-Gericke, A.; Schlögl, R.; Neese, F. First Principles Calculations of the Structure and V L-Edge X-Ray Absorption Spectra of $\mathrm{V}_{2} \mathrm{O}_{5}$ Using Local Pair Natural Orbital Coupled Cluster Theory and SpinOrbit Coupled Configuration Interaction Approaches. Phys. Chem. Chem. Phys. 2013, 15, 7260.

(73) Staemmler, V. The Cluster Approach for the Adsorption of Small Molecules on Oxide Surfaces. Top. Organomet. Chem. 2005, 12, 219-256.

(74) Rees, J. A.; Wandzilak, A.; Maganas, D.; Wurster, N. I. C.; Hugenbruch, S.; Kowalska, J. K.; Pollock, C. J.; Lima, F. A.; Finkelstein, K. D.; DeBeer, S. Experimental and Theoretical Correlations between Vanadium K-Edge X-Ray Absorption and $\mathrm{K} \beta$ Emission Spectra. JBIC, J. Biol. Inorg. Chem. 2016, 21, 793-805.

(75) Bergner, A.; Dolg, M.; Küchle, W.; Stoll, H.; Preuß, H. Ab Initio Energy-Adjusted Pseudopotentials for Elements of Groups 1317. Mol. Phys. 1993, 80, 1431-1441.

(76) Kaupp, M.; Schleyer, P. v. R.; Stoll, H.; Preuss, H. Pseudopotential Approaches to $\mathrm{Ca}, \mathrm{Sr}$, and Ba Hydrides. Why Are Some Alkaline Earth MX2 Compounds Bent? J. Chem. Phys. 1991, 94, 1360-1366.

(77) Desgranges, L.; Grebille, D.; Calvarin, G.; Chevrier, G.; Floquet, N.; Niepce, J.-C. Hydrogen Thermal Motion in Calcium Hydroxide: $\mathrm{Ca}(\mathrm{OH})_{2}$. Acta Crystallogr., Sect. B: Struct. Sci. 1993, 49, $812-817$

(78) Brackett, E. B.; Brackett, T. E.; Sass, R. L. The Crystal Structure of Calcium Bromide. J. Inorg. Nucl. Chem. 1963, 25, 1295-1296. 
(79) Speziale, S.; Duffy, T. S. Single-Crystal Elastic Constants of Fluorite $\left(\mathrm{CaF}_{2}\right)$ to $9.3 \mathrm{GPa}$. Phys. Chem. Miner. 2002, 29, 465-472.

(80) Wyckoff, R. W. G. Crystal Structures, 2nd ed.; John Wiley: New York, 1963.

(81) Verbraeken, M. C.; Suard, E.; Irvine, J. T. S. Structural and Electrical Properties of Calcium and Strontium Hydrides. J. Mater. Chem. 2009, 19, 2766-2770.

(82) Zolotoyabko, E.; Caspi, E. N.; Fieramosca, J. S.; Von Dreele, R. B.; Marin, F.; Mor, G.; Addadi, L.; Weiner, S.; Politi, Y. Differences between Bond Lengths in Biogenic and Geological Calcite. Cryst. Growth Des. 2010, 10, 1207-1214.

(83) Krewald, V.; Retegan, M.; Cox, N.; Messinger, J.; Lubitz, W.; DeBeer, S.; Neese, F.; Pantazis, D. A. Metal Oxidation States in Biological Water Splitting. Chem. Sci. 2015, 6, 1676-1695.

(84) Carlson, T. A.; Nestor, C. W. Calculation of Electron Shake-off Probabilities as the Result of X-Ray Photoionization of the Rare Gases. Phys. Rev. A: At., Mol., Opt. Phys. 1973, 8, 2887-2894.

(85) Ito, Y.; Tochio, T.; Yamashita, M.; Fukushima, S.; Vlaicu, A. M.; Syrocki, Ł.; Słabkowska, K.; Weder, E.; Polasik, M.; Sawicka, K.; Indelicato, P.; Marques, J. P.; Sampaio, J. M.; Guerra, M.; Santos, J. P.; Parente, F. Structure of High-Resolution $\mathrm{K} \beta_{1,3} \mathrm{X}$-Ray Emission Spectra for the Elements from Ca to Ge. Phys. Rev. A 2018, 97, 1-10.

(86) Glatzel, P.; Bergmann, U. High Resolution 1s Core Hole X-Ray Spectroscopy in 3d Transition Metal Complexes - Electronic and Structural Information. Coord. Chem. Rev. 2005, 249, 65-95.

(87) Hall, E. R.; Pollock, C. J.; Bendix, J.; Collins, T. J.; Glatzel, P.; DeBeer, S. Valence-to-Core-Detected X-Ray Absorption Spectroscopy: Targeting Ligand Selectivity. J. Am. Chem. Soc. 2014, 136, 1007610084 .

(88) Pollock, C. J.; Lancaster, K. M.; Finkelstein, K. D.; DeBeer, S. Study of Iron Dimers Reveals Angular Dependence of Valence-toCore X-Ray Emission Spectra. Inorg. Chem. 2014, 53, 10378-10385.

(89) Askerka, M.; Vinyard, D. J.; Wang, J.; Brudvig, G. W.; Batista, V. S. Analysis of the Radiation-Damage-Free X-Ray Structure of Photosystem Ii in Light of Exafs and QM/MM Data. Biochemistry 2015, 54, 1713-1716.

(90) Davis, K. M.; Pushkar, Y. N. Structure of the Oxygen Evolving Complex of Photosystem II at Room Temperature. J. Phys. Chem. B 2015, 119, 3492-3498.

(91) Amin, M.; Askerka, M.; Batista, V. S.; Brudvig, G. W.; Gunner, M. R. X-Ray Free Electron Laser Radiation Damage through the SState Cycle of the Oxygen-Evolving Complex of Photosystem II. J. Phys. Chem. B 2017, 121, 9382-9388.

(92) Thorp, H. H. Bond Valence Sum Analysis of Metal-Ligand Bond Lengths in Metalloenzymes and Model Complexes. Inorg. Chem. 1992, 31, 1585-1588.

(93) Narzi, D.; Mattioli, G.; Bovi, D.; Guidoni, L. A Spotlight on the Compatibility between XFEL and $\mathrm{Ab}$ Initio Structures of the Oxygen Evolving Complex in Photosystem II. Chem. - Eur. J. 2017, 23, 69696973.

(94) Lohmiller, T.; Krewald, V.; Sedoud, A.; Rutherford, A. W.; Neese, F.; Lubitz, W.; Pantazis, D. A.; Cox, N. The First State in the Catalytic Cycle of the Water-Oxidizing Enzyme: Identification of a Water-Derived $\mu$-Hydroxo Bridge. J. Am. Chem. Soc. 2017, 139, 14412-14424.

(95) Matsukawa, T.; Kawamori, A.; Mino, H. Electron Paramagnetic Resonance Study of the Magnetic Structure of the $S_{1}$-State in Oriented Oxygen Evolving Photosystem II Membranes. Spectrochim. Acta, Part A 1999, 55, 895-901.

(96) Boussac, A.; Rutherford, A. W.; Sugiura, M. Electron Transfer Pathways from the $\mathrm{S}_{2}$-States to the $\mathrm{S}_{3}$-States Either after a $\mathrm{Ca}^{2+} / \mathrm{Sr}^{2+}$ or a $\mathrm{Cl}^{-} / \mathrm{I}^{-}$Exchange in Photosystem II from Thermosynechococcus Elongatus. Biochim. Biophys. Acta, Bioenerg. 2015, 1847, 576-586.

(97) Kusunoki, M. S1-State $\mathrm{Mn}_{4} \mathrm{Ca}$ Complex of Photosystem II Exists in Equilibrium between the Two Most-Stable Isomeric Substates: XRD and EXAFS Evidence. J. Photochem. Photobiol., B 2011, 104, 100-110.

(98) Tanaka, A.; Fukushima, Y.; Kamiya, N. Two Different Structures of the Oxygen-Evolving Complex in the Same Polypeptide
Frameworks of Photosystem II. J. Am. Chem. Soc. 2017, 139, 17181721.

(99) Pal, R.; Negre, C. F. A.; Vogt, L.; Pokhrel, R.; Ertem, M. Z.; Brudvig, G. W.; Batista, V. S. S ${ }_{0}$-State Model of the Oxygen-Evolving Complex of Photosystem II. Biochemistry 2013, 52, 7703-7706. 